\title{
BMJ Open A qualitative approach in determining the patient-centered information and supportive care needs of cancer patients in Singapore
}

Gek Phin Chua (D) , ${ }^{1}$ Hiang Khoon Tan ${ }^{2,3}$

To cite: Chua GP, Tan HK. A qualitative approach in determining the patientcentered information and supportive care needs of cancer patients in Singapore. BMJ Open 2020;10:e034178. doi:10.1136/ bmjopen-2019-034178

- Prepublication history and additional material for this paper are available online. To view these files, please visit the journal online (http://dx.doi. org/10.1136/bmjopen-2019034178).

Received 09 September 2019 Revised 07 January 2020 Accepted 15 January 2020

D) Check for updates

C Author(s) (or their employer(s)) 2020. Re-use permitted under CC BY-NC. No commercial re-use. See rights and permissions. Published by BMJ.

${ }^{1}$ Patient and Family Education, National Cancer Centre

Singapore, Singapore, Singapore

${ }^{2}$ Division of Division of

Community Outreach and

Philanthropy, National Cancer

Centre Singapore, Singapore,

Singapore

${ }^{3}$ Division of Surgical Oncology,

National Cancer Centre

Singapore, Singapore, Singapore

Correspondence to

Ms Gek Phin Chua;

ncccgp@nccs.com.sg

\section{ABSTRACT}

Objectives To qualitatively interpret the information and supportive care needs perceived by cancer patients undergoing treatment in order to get a deeper appreciation of patients' needs and concerns. The intended outcome is to provide baseline knowledge for improving patientcentred strategies to better meet the information and supportive needs of patients.

Design A qualitative research approach, based on conventional content analysis, was used throughout the research process. The three open-ended questions obtained from a previous quantitative study guided the researchers to explore the information and supportive care needs of patients. Data from patients' responses were analysed and coded in themes.

Participants and setting Patients attending the Ambulatory Treatment Unit of the National Cancer Centre Singapore were invited to participate in the study. We determined from these subjects the type of information that cancer patients need, and to measure the extent to which these information needs are met by measuring patients' level of satisfaction. Included in the quantitative study were three open-ended questions designed to gain a deeper understanding of their needs and concerns. All subjects were aged 21 years and above and able to understand and communicate in English/Mandarin. They were also aware of their diagnosis, they were not cognitively impaired and were not at the end-of-life situation.

Results A variety of information and supportive care needs were identified, and three specific areas of concerns were identified: (1) psychosocial and supportive care needs, (2) information needs and (3) information delivery by professionals.

Conclusion The information and supportive care needs expressed were consistent with issues of cancer patients undergoing treatment. The strategies to improve patients' coping abilities through patient-centred care are discussed. Further studies assessing the barriers of information provision by healthcare professionals should provide more detailed knowledge about unmet information needs.

\section{INTRODUCTION}

The diagnosis of cancer stresses any individual; this is related to the symptoms of the
Strengths and limitations of this study

- This study attempted to explore in more depth, the information and supportive care needs of the cancer patients receiving treatment in Singapore with qualitative data obtained from a large quantitative study.

- The analysis generated three themes that provide a deeper understanding of the needs and support required to better deliver patient-centered care for cancer patients in Singapore as there is no information on this question to date.

- Respondents were recruited from the only one site and may not be representative of all the cancer patients in Singapore. However, given that this is a qualitative study, the issue of generalisability is less of a concern.

disease and to the psychology of its affliction. ${ }^{1}$ To many people, cancer implies a death sentence; to others it implies suffering and pain. ${ }^{34}$ Even today, cancer remains a fatal disease for a significant number of patients, despite considerable advances in treatment. Compounding this stress is the need for treatment, which may intrude into every area of the patient's life. As a result, cancer patients face many adjustments, not only to the disease itself but also to treatment regimes, both of which may have significant and distressing physical and emotional effects. ${ }^{5-7}$ The patients' emotional reactions to their illness, along with their coping responses, can influence the course and outcome of the disease. ${ }^{8}$

Providing cancer information and support is an important aspect of the healthcare professional's role. When done well, such provision and support have been found to help patients in their coping process and improve their quality of life. Patient-centred care is defined as providing care that is respectful and responsive to individual patients preferences, needs and values and ensuring that patient values guide all clinical 
decisions'. ${ }^{9}$ In patient-centred care, care decisions are based on knowledge of patient values, preferences and expressed needs as well as treating patients and their families with respect and honour, including them as partners in care, and regarding them as safety allies. ${ }^{10}$ The concept of patient centeredness is advocated as an important attribute of high-quality care. The Institute of Medicine ${ }^{9}$ further elaborated on some of the attributes of patient-centred care in the oncology setting. These attributes are: (1) patient education and empowerment; (2) patient-centred communication, which involves the patient, family and friends; explains treatment options; and includes patients in treatment decisions to reflect patients' values, preferences and needs; (3) coordination and integration of care and (4) provision of emotional support as needed, such as relieving fear and anxiety and addressing mental health issues. In essence, patientcentred cancer care focuses on delivering care according to the preferences and needs as defined by patients themselves and their families.

Cancer patients need information to help them cope with the disease, make decisions about treatment, manage side effects and learn self-care skills. Some patients may need emotional support to help cope with their anxiety and distress. Studies have indicated that the patients undergoing cancer treatment have considerable information and supportive care needs and that these needs can vary considerably across individuals. ${ }^{11-15}$ In delivering patient-centred care, it is imperative to determine the particular information and supportive care needs of patients in order to address these efficiently and effectively.

In this study, we examine open-ended responses from a quantitative study we published previously ${ }^{16}$ in order to reinforce and to get a deeper appreciation of patients' needs and concerns. We used the conventional content analysis method throughout the research process to unravel the themes from the large set of open-ended responses. The intended outcome of this study is to provide baseline knowledge for improving patient-centred strategies to better meet the information and supportive care needs of patients during cancer treatment.

\section{METHODS}

Patients attending the Ambulatory Treatment Unit of the National Cancer Centre Singapore were invited to participate in the study. For inclusion in the study, participants had to be diagnosed with cancer and receiving treatment; were able to understand and communicate in English/ Mandarin; were neither cognitively impaired nor terminally ill; and had to be at least 21 years old.

\section{Procedures}

Participation in the study was voluntary and respondents were free to withdraw consent or discontinue participation from the study at any time without any effect on the treatment or care. Written consent was obtained from all the respondents after detailed explanation of the study's purpose and procedure was provided, and before the administration of the questionnaire survey. Each questionnaire was coded with a unique identification number to ensure confidentiality, with respondents being not personally identifiable in the study.

\section{Data collection}

Data were collected over a 5-month period from 2015 to 2016 by a research assistant who was proficient in both English and Chinese language and was thoroughly briefed by the principal investigator regarding the data collection process including sampling and confidentiality. Data were recorded by the research assistant and verification of all data recorded was conducted by both the principal investigator and one other researcher.

In the current study, we examined the following openended questions: (1) What information provided to you is either insufficient to meet your needs or has not been given? (2) What are the aspects of cancer information delivery and support services can we improve on to help you cope with your cancer journey? and (3) Has there been any other information we can (but did not) provide that can help you cope better? These open-ended questions are intended to give respondents an opportunity to provide more detailed or personalised content to supplement the fixed responses to most of the questionnaire in order to get a deeper significance of patient's needs and concerns. A qualitative research approach, based on conventional content analysis, was used throughout the research process.

\section{Data analysis}

A thematic qualitative analysis of the free-text items was undertaken manually (responses were translated where required) for those respondents who responded to the above three open-ended questions. Data were initially categorised according to responses to questions (figure 1). Data from each question were then examined systematically to identify particular categories of meanings following the qualitative conventional content analysis. ${ }^{17-19}$ Meaningful units were initially identified by reading. Then, condensed units were described, by identifying the underlying meaning of the units. The next phase was identifying the codes. Finally, a collection of different codes-and sub-codes-were identified as categories in a thematic area. To increase the validity of the findings, an independent researcher reviewed the categories to ensure agreement in the coding system. The findings were also verified by a nurse expert in qualitative research.

In the result section, quotes are used to illustrate and reflect the responses given by the respondents. Quotes were selected on the basis of the criteria that a code should illustrate the category and meaning sufficiently and it represents the opinions of different respondents. The participants were not personally identifiable. Numbers and letters are used to represent male or female 


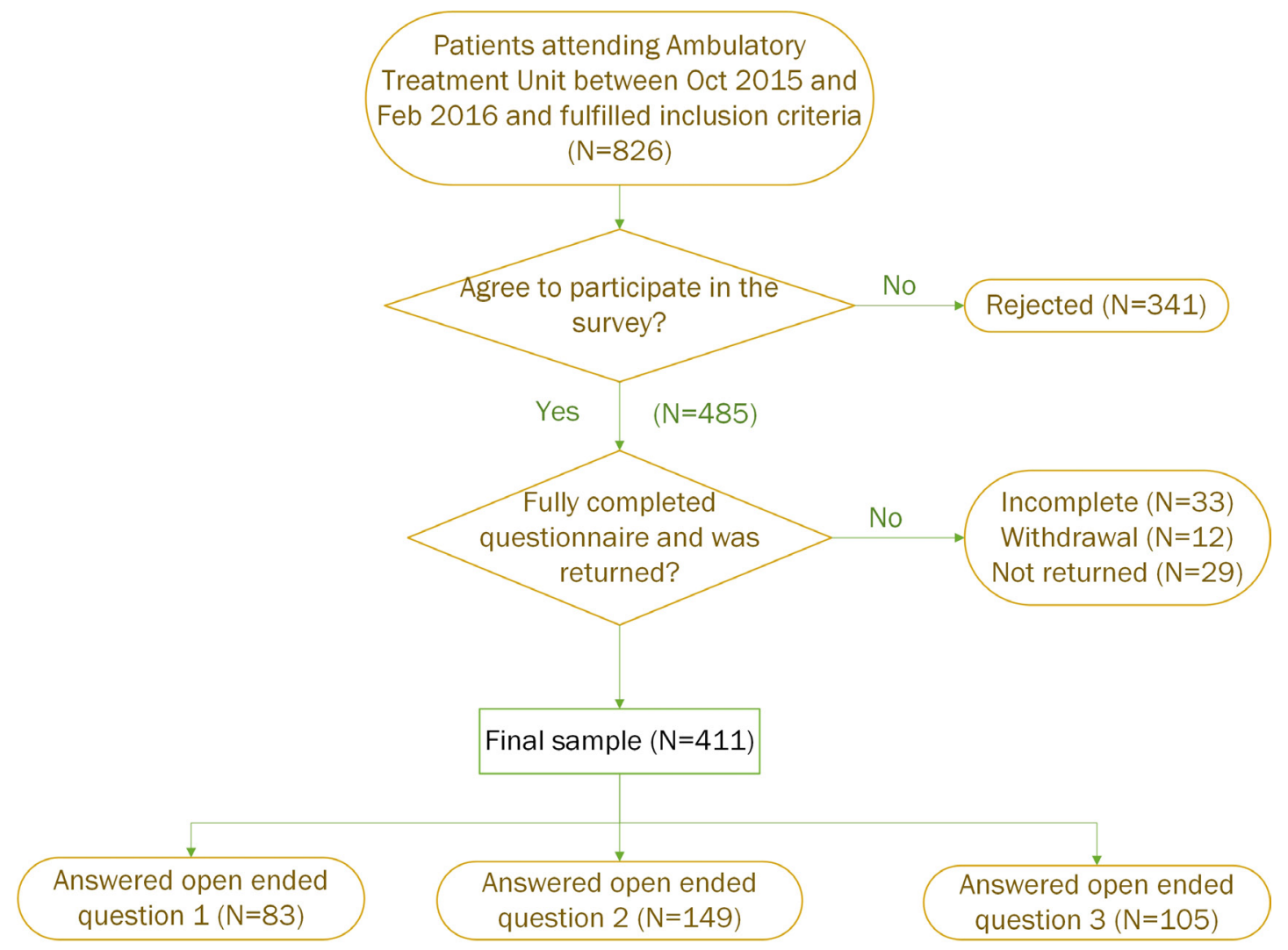

Figure 1 Flowchart of patient recruitment.

respondents. The Standard for Reporting Qualitative Research checklist is presented in online supplementary appendix 1 (O’Brien et al, 2014). ${ }^{20}$

\section{Patient and public involvement}

Fifteen oncology nurse experts reviewed the questionnaire and a pilot study was conducted on eleven eligible patients. No item was deleted from the questionnaire during the pilot study and no further refinements were necessary. The questionnaire was subsequently used in the survey to evaluate self-reported information needs and level of satisfaction with the information received while undergoing cancer treatment.

\section{RESULTS}

Table 1 summarises the demographic characteristics of the respondents. More women than men participated in this study. Three hundred and sixty-five $(88 \%)$ of the respondents ranged from 41 to 60 years of age. They were mainly married, fairly educated and newly diagnosed with cancer. The majority of participants were Chinese. Breast, colorectal and lung cancers were the most common among the participants.

Three themes were identified: (1) psychosocial and supportive care needs, (2) information needs, and (3) quality of information delivery. A summary of respondents' responses organised according to themes and subthemes is given in table 2 .
Theme 1: psychosocial and supportive care needs The need for professional counselling

Respondents felt the greatest need to receive counselling, with some feeling that this should be provided not only to patients but also to their families, including caregivers. Respondents also felt that counselling should be provided at the time of diagnosis and should include knowledge of coping and communication skills. The quotes below provide examples of this need perception:

(M001) To have face-to-face counselling session to both patients and their families during the time when they are diagnosed. Guide them on how to face the situation, what to do, and how to communicate.

(F001) It would be good if all new patients can go through a counselling session to satisfy their needs for emotional support.

(M002) After the first treatment, refer the patient to talk to a social worker or counsellor to tell him or her more about their cancer and other information.

\section{Support groups}

The benefits of communicating with others in similar circumstances and/or support given by support groups for all people affected by cancer were noted by many responders. The comments below emphasise the need for support groups and the importance of speaking to others in similar circumstances as information from medical personnel may be insufficient to address their needs. They 


\begin{tabular}{|c|c|}
\hline Characteristics & $\mathbf{N}(\%)$ \\
\hline \multicolumn{2}{|l|}{ Sex } \\
\hline Male & $152(37)$ \\
\hline Female & $259(63)$ \\
\hline \multicolumn{2}{|l|}{ Age (years) } \\
\hline $21-40$ & $45(10.9)$ \\
\hline $41-60$ & $223(54.3)$ \\
\hline 60 and above & $142(34.5)$ \\
\hline Unknown & 1 \\
\hline \multicolumn{2}{|l|}{ Ethnicity } \\
\hline Chinese & $317(77.1)$ \\
\hline Malay & $46(11.2)$ \\
\hline Indian & $20(4.9)$ \\
\hline Others & $27(6.6)$ \\
\hline Unknown & 1 \\
\hline \multicolumn{2}{|l|}{ Marital status } \\
\hline Married & 320 (77.9) \\
\hline Non married & $85(20.7)$ \\
\hline Unknown & 6 \\
\hline \multicolumn{2}{|l|}{ Highest level of education } \\
\hline Primary or less & $81(19.7)$ \\
\hline Secondary/higher secondary & $213(51.8)$ \\
\hline Tertiary & 109 (26.5) \\
\hline Unknown & $8(2)$ \\
\hline \multicolumn{2}{|l|}{ Cancer type } \\
\hline Breast & $115(28.0)$ \\
\hline Colon/rectal & $60(14.6)$ \\
\hline Lung & $52(12.6)$ \\
\hline Lymphoma & $26(6.3)$ \\
\hline Nasopharynx & $21(5.1)$ \\
\hline Ovarian & $20(4.9)$ \\
\hline Liver & $16(3.9)$ \\
\hline Stomach & $14(3.4)$ \\
\hline Bone & $14(3.4)$ \\
\hline Pancreas & $13(3.2)$ \\
\hline Prostate & $10(2.4)$ \\
\hline Others & $38(9.2)$ \\
\hline Unknown & 39 \\
\hline
\end{tabular}

Table 2 Main categories of cancer patients' information and supportive care needs

\begin{tabular}{lll}
\hline \multicolumn{1}{|c}{ Themes } & Subthemes \\
\hline 1. & $\begin{array}{l}\text { Psychosocial and } \\
\text { supportive care needs }\end{array}$ & $\begin{array}{l}\text { Professional counselling } \\
\text { Support groups }\end{array}$ \\
$\begin{array}{lll}\text { 2. } & \begin{array}{l}\text { What to do- } \\
\text { Information needs on: }\end{array} & \text { Fear of recurrence } \\
& & \text { Dietary advice } \\
\text { Complementary medicine }\end{array}$ \\
\hline 3. & $\begin{array}{l}\text { Quality of information } \\
\text { delivery }\end{array}$ & Need for more time \\
\hline & & Information better delivered \\
\hline
\end{tabular}

regarding the side effects. Information on support group is needed.

(F003) Support group tips, for example, cancer survivors or patients who have done certain treatments could give advice through their experiences. Met the colorectal support group during my stay at the wards and they have done a very good job. I am grateful for the sharing from the support group especially those who have been through the same route. I would love to join them as well, as I believe patients' experience will be more convincing to other patients.

Respondents also wanted a support group for their respective types of cancer and the quote below highlights the need.

(F004) Setting up a support group for lymphoma cancer patients is of top priority as when I was diagnosed in Jan 2014, tried so hard to get Dr. to get her patients to share their experiences and look for support groups but unfortunately there are none.

Obtaining information on how to join a support group was another expressed need. Respondents also indicated the lack of publicity on the existence of support groups, with many being unaware of the services that were available; some even provided suggestions on improving the provision of information on support services.

(F005) Information on how to join a support group at an early stage of diagnosis so as to enable the patient to get connected to cancer survivors who had similar diagnosis, obtain life experiences and encouragement to accept the diagnosis and be ready to cope with the treatment and life.

(F006) Received support from social worker not at the initial stage. Support services are not well publicized and no counselling for patients. Suggest to have a counter that focuses in providing information on support services. 


\section{Theme 2: information needs}

What to do

Respondents indicated that they had many information needs in order to help in decision-making and allay their anxiety; these include needs for information on diets, complementary therapies and finances. Chances of and prevention of relapses, late effects and alternative treatment options should current treatments fail were other information needs identified by respondents. For example:

(F007) Subsequent treatment for patients if the current treatment is not effective. For example, what other options to explore if current treatment failed.

(F008) All patients have fear of recurrence and survivorship. Addressing these fears help to relieve stress.

(F009) Being informed about possible future problems such as late effects and chances of recurrence.

\section{What to eat: dietary advice}

The need for dietary advice was indicated by many respondents.

(M003) Types of food that can fight cancer.

(M004) Nutrition advices that include types of food, types of fruit, what not to eat and what to eat. This information would help in the treatment and recovery.

Respondents also requested for access to a nutritionist to address some of their concerns.

(M005) Nutrition information such as food that help and food to avoid. Having a nutritionist for patients to consult as patients are always flooded with food information and is difficult to differentiate which are true.

(F010) There should be counselling or advice on nutrition during and after chemo treatment. Access to consult a nutritionist would be a good start. Food is the key to get cured.

(F011) Other than doctors, I did not receive inputs from dietitian as part of the care plan. Issue of swallowing difficulties and poor appetite not addressed.

\section{Complementary therapy}

Respondents requested for information on complementary therapies [eg, supplements and traditional Chinese medicine (TCM)], as the following quotes from patients indicate:

(M003) TCM and related information.

(F012) Complementary nutrition or tonic (eg, Chinese medicine) or supplements.

(F013) More information on complementary therapy would be important for effective radiation therapy as patients need to make informative decision. This includes the impacts of complementary therapy on radiation therapy (eg, alkaline water, lingzi and etc).
Financial needs

Information about cost of treatment as well financial assistance was another concern raised by the respondents. The following quotes demonstrate this need:

(F014) Financial costs of treatment should be more forthcoming.

(F015) Financial aspect of whole treatment was not clearly defined and explained. I have to roughly estimate the cost of one whole treatment.

(F016) Inform about financial information such as chemotherapy costs and other possible medication costs so that we can plan for long term financial needs on treatment.

Many respondents also indicated that they needed information on financial assistance and support.

(F017) Informing us about how to access to financial help and support.

(F018) No financial support advice is given.

\section{Theme 3: quality of information delivered by professionals} Need more time from professionals

Some respondents expressed difficulty while talking with the doctor due to short consultation time. They wanted more face time with the specialists for discussion and explanations.

(M005) It would be more helpful if the doctors can spend more time explaining about the patient's conditions and treatment options.

(M006) More time and patience are needed from the doctors and specialists to explain all information and with smiles if possible.

How information could be better delivered

Respondents wanted the doctors to be more thorough and speak in plain language instead of using technical jargon.

(M005) Avoid jargons in scan reports. Explain the reports in simple words and more information on those negative reports.

(F014) They can be more thorough when explaining test results to patients, especially medical terms.

Aside from the above, the respondents also indicated that healthcare professionals should display more sensitivity on how they deliver their message.

(F019) They do not spend time talking and explaining to patients. Patients have to ask questions continuously before they get their answers. Sometimes they may imply that 'I am the doctor, don't question me'.

(F010) He did not give me a lot of information and sounded like a recorder, kept on repeating the same information. When I asked how I can be an active participant in my treatment, he answered me that there was nothing I could do. 
(F020) Provision of information on past records and studies of the available treatment may appease the patient's apprehension and decision making on accepting them. However, such information was given abruptly only upon enquiring, which can be rather discouraging.

In further addition to that, the respondents also suggested on the type of information and how it could be relayed.

(M007) Information about how to cope and overcome. Having doctors to inform/encourage/give hope to patients such as telling positive life examples.

Respondents wanted to have easy access to professionals, with some respondents indicating the manner they prefer to be helped in order to alleviate their anxiety and aid in faster recovery.

(F003) The doctors, my surgeons for both operations did very good job and I have full confidence in them. Building rapport and good relationship with the surgeons can help a lot. Especially my colorectal surgeon makes sure he visits to review me twice daily in the ward and even on weekends at least once. This warms me a lot and gave me the needed good vibes to faster recovery. It is very important that patients have a way to communicate with the oncologist or surgeon as in times of doubt, patients can clear their doubts immediately and could avoid time wastage or even save some lives rather than having to wait or waste A\&E resources for cases that could have been resolved just by a confirmation over email or WhatsApp or text.

(F021) My doctor gave his email address and answered my urgent questions on side effects very promptly. It helped me feel better immediately when I read his email confirming that nothing is worrisome.

\section{DISCUSSION}

In summary, the three themes reflect the information and supportive care needs of cancer patients undergoing treatment. Some of the needs expressed by respondents were shared by more than one respondent and are consistent with issues identified in the literature.

\section{Psychosocial and supportive care needs}

Cancer patients indicated the need for professional counsellors and to learn coping skills from support groups.

Emotional distress is a normal response to a diagnosis of cancer ${ }^{12821}$ and happens throughout the disease trajectory. ${ }^{22-24}$ A great majority of cancer patients experience fear, depression and a constant underlying tension during their treatment. ${ }^{25}$ Emotional support is important to patients during their illness and can be obtained from different people and services. ${ }^{46}$ Psychosocial interventions have been found to help patients cope better with distressing situations and positively improve the affective state. ${ }^{27}$ Individual counselling, especially during the initial phase of diagnosis, has been identified as an important aspect of supportive care by the respondents. ${ }^{2629}$ Although one-to-one counselling is available to our patients, our findings indicate a need for more awareness (by patients and medical staff) of such services. At the same time, there is also a deeper need to find out why patients were not referred for counselling. A study done justified this need. ${ }^{30}$ Studies have shown that there is a marked tendency to underestimate the level of depressive symptoms in cancer patients, ${ }^{30} 31$ and that oncologists' recommendations for supportive counselling did not correlate with patient distress or the amount of perceived support but rather with disease progression and the amount of denial behaviour displayed. ${ }^{30}$

Respondents had also indicated their need for support groups. Cancer survivors can play a complementary role as messengers of hope and share their success stories of how they overcame their emotional and physical challenges during treatment. Studies have demonstrated the benefits of support groups for cancer patients, including generating feelings of interconnectedness, confidence, hope, support, affirmation, usefulness, less depression and less anxiety. In addition, other benefits include having more knowledge about their illness, better relationships with caregivers, fewer sexual difficulties, more participation in leisure activities and a higher quality of life. ${ }^{32-34}$ Despite these positive aspects of support groups, there are also negative effects and these include wrong information given, pessimistic attitude and deteriorating condition of the group members ${ }^{32} 35$ that adversely affected patients' emotional state. In addition, Helgeson $e t a l^{36}$ showed that peer discussion groups were helpful for patients who lacked support from their partners or physicians but harmful for patients who had high levels of support. Therefore, it is important to be cautious and carefully identify patients who can benefit from participation in support groups. An awareness of patients' support system is thus important and only those who lack social support should be referred to peer-support groups.

Respondents in our study also indicated that they preferred joining support groups comprising of peers inflicted with the same malignancy and that they preferred to join support groups for emotional support and coping skills. This agrees with the results of Devitt $e t$ $a l,{ }^{37}$ who further established that differing views existed in patients and healthcare professionals on who should be facilitating the support group and how support groups should be conducted. As many of the respondents in this study indicated an interest in attending support groups, there is clearly an unmet need for support groups. Due to differing patients' needs as well as the potential negative impact of support groups, it is important that in addition to identifying patients who will benefit from support groups, it is also paramount that healthcare providers determine the preferred models of support and the barriers to the uptake of support programmes so that care delivery will best match patients' needs and thus, 
encourage participation. This will help to ensure the effective and efficient use of scarce resources.

\section{Information needs}

Our study on the information need of cancer patients agrees with those of the previous studies, which indicate available treatment options, chances of recurrence and survival outcomes as essential information to assist decision-making. ${ }^{38}$ Fear of recurrence is one of the most common psychological concerns reported by cancer patients ${ }^{39-41}$ is associated with functional impairment ${ }^{41}$ and can be a significant psychological burden if unaddressed. ${ }^{39} 4042$ In order to help address this aspect of emotional distress, patients should therefore be encouraged to verbalise their fear so as to minimise the threat of psychological distress and should also be taught what to look out for to detect recurrence. They should also be encouraged to focus on strengths and positive qualities to enhance control over their fear. ${ }^{41}$ Further studies would help determine the extent of this fear and if it leads to irrational thought or behaviour and whether it negatively affects their quality of life.

Food is of great interest and concern to many respondents. Dietary advice, especially on the foods to eat and avoid, was another recurrent need identified in this study. Respondents also indicated a need for access to a nutritionist. Good nutrition for patients undergoing cancer treatment is important as clinical malnutrition in patients with malignant disease is a frequent problem associated with progressive tumour growth and cancer therapy. ${ }^{43}{ }^{44}$ Significant nutritional deficits can delay and accentuate complications related to primary therapy. Surgery, chemotherapy and radiation therapy may limit oral intake for prolong periods of time and may leave the patient with insufficient reserves to sustain normal life. ${ }^{645}$ Therefore, maintenance of adequate nutritional state is a 'sine qua non' for efficiency of the therapy. ${ }^{46}$ As adequate nutritional support is an integral part of a cancer patient's treatment and malnutrition can complicate the course and outcome of treatment, early intervention of nutritional support is important. Studies have also shown that adequate nutritional support may improve immunocompetence in patients receiving radiation or chemotherapy ${ }^{47-50}$ and that good nutritional status may increase response rates to therapy and also help to promote better tolerance to therapy.

However, good nutritional intake may be compromised by cultural beliefs and traditions. In Asian (especially Chinese) cultures, concepts of nutritious food and a balanced diet may differ from Western concepts. The Chinese believe that health is maintained in the balance of Yin and Yang through food, and there are food taboos especially when one is suffering from cancer. Studies have also shown that it is not uncommon for patients to avoid types of food $^{51}$ because of perceptions. ${ }^{52}$ It is therefore important to address this need and a dietitian's support should be sought if required. Dietary support is also needed because a person who is sick and fearful (particularly with a cancer diagnosis) will tend to believe in anything. This can be detrimental to patients because they may be advised by family members, friends or cancer survivors to avoid food that may be nutritious but considered 'toxic'. It appears from our study that the need for nutritional counselling was underestimated, a result reported by Geirsdottir and Thorsdottir. ${ }^{53}$ Therefore, besides addressing their food concerns, a greater understanding of patients' dietary beliefs and practices would also better enhance culturally appropriate interventions and nutritional screening may be necessary so that early referral may be made to a dietitian.

Respondents also wanted more information about complementary therapies, especially information relating to TCM. The interest in TCM is not uncommon as TCM is readily available in Singapore and its concurrent use with Western medicine is common. ${ }^{54}$ It is also common for patients and their families to be encouraged to use herbal products to rid off the cancer or boost immunity. Studies on the use of complementary and alternative therapies (CAM) in cancer patients have cited the natural and non-toxic qualities of CAM, dissatisfaction with conventional treatment, perceived boost in the immune system and prolongation of life, improvement in quality of life, symptomatic relief, and encouragement from family and friends as the main reasons for their use. ${ }^{55-57}$ However, the integration and utilisation of Western medicines and TCM or other herbal products may pose risks when the patients are being treated with different medications from different sources for the same illness episode as herbal products may contain contaminants, are toxic, interact with biomedical drugs, or interfere with a coexisting disease, delay of conventional therapy and interference with prescribed treatment, both palliative or curative. ${ }^{589}$ Besides this, the use of CAM may dissuade some patients from receiving effective treatments as revealed study has shown that $37.5 \%$ of patients expect CAM therapies to cure their disease ${ }^{57}$ Richardson et $a l \mathrm{~s}^{57}$ study also showed that most of the patients who used CAM did not feel they could discuss this topic with their physician.

Due to the concerns associated with the practice of CAM, it is crucial for healthcare professionals to explore the use of CAM with their patients and encourage them to bring up issues so as to assist in making informed and intelligent decisions about their choice of care. In addition, healthcare professionals can help monitor patients for drug-herb interactions. Such interest may prompt patients to be more open to disclosing their practices, improves the communication process, and could also possibly encourage compliance with conventional treatment.

Respondents indicated a need for financial information relating to costs of treatment, and sources of financial support. Major illness, such as cancer, can severely deplete family finances due to the cost of treatment, loss of work and altered care needs. Studies have shown the financial burden of cancer to be a major source of worry, ${ }^{6061}$ particularly for those using adjuvant chemotherapy ${ }^{62}$ and can 
negatively impact quality of life. ${ }^{63}$ Addressing this, information needs will enable patients to make informed decisions about their care and may help lighten their financial burden. This aspect of care delivery is also mandated by The Private Hospitals and Medical Clinics Act of Singapore $^{64}$ that decrees the provision of financial counselling for patients by healthcare providers.

\section{Quality of information delivered by professionals}

Respondents have indicated that they want more time with their physicians in explaining their condition and treatment options. At the same time, the respondents indicated a desire for the physicians' communication skills to be enhanced. The key component of patientcentred care is effective patient-clinician communication and shared decision-making. ${ }^{9}$ Studies show that good physician communication is significantly correlated with patient adherence, ${ }^{6566}$ satisfaction, ${ }^{67}$ emotional support ${ }^{35}$ and is not related to the length of interactions. ${ }^{67}$ Communication is an important component of patient-centred care and how effectively and compassionately the information is being delivered serves not only to establish a good physician-patient relationship but also to improve the patient coping skills and patient outcomes.

There are numerous factors that can negatively affect effective patient-centred communication and shared decision-making by patients and physicians. Challenges for patients include the emotional distress associated with a diagnosis of cancer, patients' lack of assertiveness, fear of being considered difficult by asking too many questions, fear of receiving substandard care, poor health literacy, information overload, unfamiliar jargon and age. ${ }^{9}$ Age, gender, culture, language, training, failure to appreciate differing information needs of patients, level of comfort in discussing certain topics (eg, poor prognosis, sexuality and terminal care), misjudgment of patient preferences and lack of time ${ }^{9}$ have been identified as challenges confronting the clinicians. Therefore, in an era where conflicting demands are imposed on medical staff and a physician's effective communication skill is important, improving the communication skills of the medical staff would help address some of these concerns.

The respondents in our study indicated a preference for easy access to their physicians and were greatly relieved when their concerns were addressed by their doctors through the internet or via telephone. This highlights their need for quick information from a reliable source. Though telecommunication may offer better access to medical staff, it is important to ensure that safeguards are in place when communicating electronically with patients. Caution that such modes of communication must never replace the crucial interpersonal contact that is the basis of patient-physician relationship ${ }^{68}$ should be exercised.

\section{Limitations}

The limitations of this study, as with all qualitative studies, are linked to sample selection. First, the data were collected from one ambulatory cancer centre, with self-reporting being the only method of data collection; the data obtained may thus not be representative of the overall population of cancer patients undergoing treatment. Second, this was a convenience sample and data were extracted from a larger study, so a potential selection bias has to be considered. It may also exclude those patients with a higher interest to participate but were unable to do so because they were not undergoing treatment. However, given the qualitative nature of the data obtained, the results of this study is not intended to be generalised to the broader population of patients with cancer or any specific cancer types. Finally, there is another potential bias from the previously established professional relationship with the oncologists and the healthcare professionals in our centre, but on the other hand, this in-depth study provides some important insights into what is optimal care for cancer patients in Singapore as there was no information on this question to date. In addition, the participation of two independent analyzers on the questions of the survey increased the level of consistency in the issues reported.

\section{CONCLUSION}

In summary, this study provides insights to the optimal care of cancer patients with regard to their information and supportive care needs. The results demonstrate the challenges of providing patient-centred care and indicate that despite best efforts by our healthcare professionals in providing information and supportive care to patients, some of these services may not be able to meet the needs of these patients.

The role of the healthcare professionals in providing information and support is critical to help patients cope with the physical and psychological effects of a cancer diagnosis and treatment. Although time and resource constraints can limit the amount of information and support that can be provided in the clinical setting, knowledge of psychosocial dimensions impacting patients with cancer and effective communication skills may facilitate assessment and delivery of such services. Addressing the knowledge of psychosocial dimensions in cancer care delivery and effective communication training for healthcare professionals, as well as the specific competencies to provide patient-centred and shared decision information could be useful in addressing these gaps. Further studies assessing the barriers of information provision by healthcare professionals should provide more detailed knowledge about unmet information needs.

Acknowledgements The authors express our sincere thanks to respondents who participated in this study. Special thanks to the oncology nurse experts for their invaluable contributions and feedback on the instrument. We are greatly indebted to Ms Fernandez Ortega Maria Paz for her valuable input and feedback during data analysis and writing of this paper. The authors would also like to thank Dr Heok Hee $\mathrm{Ng}$ for his editorial assistance and those who had helped in one way or another in the study. 
Contributors GPC conceptualised and designed the study. Data collection was supervised and data were analysed, interpreted and categorised by GPC. HKT verified the data analysed and the themes formed. All authors read and approved the final manuscript.

Funding This research was made possible by a grant from Community Cancer Fund [COMCF-YR2015- MAY-NS1].

Competing interests None declared.

Patient consent for publication Not required.

Ethics approval Ethical approval was obtained from the Centralised Institutional Review Board prior to the study.

Provenance and peer review Not commissioned; externally peer reviewed.

Data availability statement All data relevant to the study are included in the article or uploaded as supplementary information. Not applicable.

Open access This is an open access article distributed in accordance with the Creative Commons Attribution Non Commercial (CC BY-NC 4.0) license, which permits others to distribute, remix, adapt, build upon this work non-commercially, and license their derivative works on different terms, provided the original work is properly cited, appropriate credit is given, any changes made indicated, and the use is non-commercial. See: http://creativecommons.org/licenses/by-nc/4.0/.

\section{ORCID iD}

Gek Phin Chua http://orcid.org/0000-0002-8920-9788

\section{REFERENCES}

1 Farpour HR, Habibi L, Owji SH. Positive impact of social media use on depression in cancer patients. Asian Pac J Cancer Prev 2017;18:2985-8.

2 Die Trill M, Trill MD. Psychological aspects of depression in cancer patients: an update. Ann Oncol 2012;23:x302-5.

3 Shahid S, Teng T-HK, Bessarab D, et al. Factors contributing to delayed diagnosis of cancer among Aboriginal people in Australia: a qualitative study. BMJ Open 2016;6:1-11.

4 Katowa Mukwato P, Mwape L, Maimbolwa CM, et al. Stress and coping with cervical cancer by patients: a qualitative inquiry. Int $J$ Psychol Couns 2015;7:94-105.

5 Pearce A, Haas M, Viney R, et al. Incidence and severity of selfreported chemotherapy side effects in routine care: a prospective cohort study. PLoS One 2017;12:e0184360.

6 Chan H-K, Ismail S. Side effects of chemotherapy among cancer patients in a Malaysian General Hospital: experiences, perceptions and informational needs from clinical pharmacists. Asian Pac J Cancer Prev 2014;15:5305-9.

7 Tsay S-L, Ko W-S, Lin K-P. The lifestyle change experiences of cancer survivors. J Nurs Res 2017;25:328-35.

8 Breitbart W. Psycho-oncology: depression, anxiety, delirium. Semin Oncol 1994;21:754-69.

9 Levit L, Balogh E, Nass S, et al. Delivering high-quality of cancer care: charting a new course for a system in crisis. Washington, DC: The National Academies Press, 2013.

10 Walton MK, Barnsteiner J. Patient-centered care. In: Sherwood G, Barnsteiner J, eds. Quality and safety in nursing: a competency approach to improving outcomes. Oxford, UK: John Wiley \& Sons, Inc, 2012: 67-90.

11 Davison BJ, Breckon EN. Impact of health information-seeking behavior and personal factors on preferred role in treatment decision making in men with newly diagnosed prostate cancer. Cancer Nurs 2012;35:411-8.

12 Bernstein KI, Promislow S, Carr R, et al. Information needs and preferences of recently diagnosed patients with inflammatory bowel disease. Inflamm Bowel Dis 2011;17:590-8.

13 Wang S-Y, Kelly G, Gross C, et al. Information needs of older women with early-stage breast cancer when making radiation therapy decisions. Int J Radiat Oncol Biol Phys 2017;98:733-40.

14 Pinto AC, Ferreira-Santos F, Lago LD, et al. Information perception, wishes, and satisfaction in ambulatory cancer patients under active treatment: patient-reported outcomes with QLQ-INFO25. Ecancermedicalscience 2014;8:425.

15 Kowalski C, Lee S-YD, Ansmann L, et al. Meeting patients' health information needs in breast cancer center hospitals - a multilevel analysis. BMC Health Serv Res 2014;14:601.

16 Chua GP, Tan HK, Gandhi M. What information do cancer patients want and how well are their needs being met? Ecancermedicalscience 2018;12:873.
17 Krippendorff K. Content analysis. In: Barnouw E, Gerbner G, Schramm W, et al, eds. International encyclopedia of communication. New York, NY: Oxford University Press, 1989: 403-7.

18 Mayring P. Qualitative content analysis. forum qualitative Sozialforschung/ Forum: qualitative social research 2000;1:Art.20.

19 Hsieh H-F, Shannon SE. Three approaches to qualitative content analysis. Qual Health Res 2005;15:1277-88.

20 O'Brien BC, Harris IB, Beckman TJ, et al. Standards for reporting qualitative research: a synthesis of recommendations. Acad Med 2014;89:1245-51.

21 Schofield PE, Butow PN, Thompson JF, et al. Psychological responses of patients receiving a diagnosis of cancer. Ann Oncol 2003;14:48-56.

22 Sarkar S, Scherwath A, Schirmer L, et al. Fear of recurrence and its impact on quality of life in patients with hematological cancers in the course of allogeneic hematopoietic SCT. Bone Marrow Transplant 2014;49:1217-22.

23 Park CL, Cho D, Blank TO, et al. Cognitive and emotional aspects of fear of recurrence: predictors and relations with adjustment in young to middle-aged cancer survivors. Psychooncology 2013;22:1630-8.

24 Petzel MQB, Parker NH, Valentine AD, et al. Fear of cancer recurrence and quality of life among survivors of pancreatic and periampullary neoplasms. Journal of Clinical Oncology 2012;30:289.

25 Husson O, Mols F, van de Poll-Franse LV. The relation between information provision and health-related quality of life, anxiety and depression among cancer survivors: a systematic review. Ann Oncol 2011;22:761-72.

26 Wu SM, Brothers BM, Farrar W, et al. Individual counseling is the preferred treatment for depression in breast cancer survivors. $J$ Psychosoc Oncol 2014;32:637-46.

27 Ding Y, Hu Y, Hallberg IR. Chinese women living with cervical cancer in the first 3 months after diagnosis: a qualitative study. Cancer Nurs 2015;38:71-80.

28 de la Torre-Luque A, Gambara H, López E, et al. Psychological treatments to improve quality of life in cancer contexts: a metaanalysis. Int J Clin Health Psychol 2016;16:211-9.

29 Pascoe S, Edelman S, Kidman A. Prevalence of psychological distress and use of support services by cancer patients at Sydney hospitals. Aust N Z J Psychiatry 2000;34:785-91.

30 Söllner W, DeVries A, Steixner E, et al. How successful are oncologists in identifying patient distress, perceived social support, and need for psychosocial counselling? Br J Cancer 2001;84:179-85.

31 Passik SD, Dugan W, McDonald MV, et al. Oncologists' recognition of depression in their patients with cancer. J Clin Oncol 1998;16:1594-600.

32 Mok E, Martinson I. Empowerment of Chinese patients with cancer through self-help groups in Hong Kong. Cancer Nurs 2000;23:206-13.

33 Cain EN, Kohorn El, Quinlan DM, et al. Psychosocial benefits of a cancer support group. Cancer 1986;57:183-9.

34 Taleghani F, Babazadeh S, Mosavi S, et al. The effects of peer support group on promoting quality of life in patients with breast cancer. Iran J Nurs Midwifery Res 2012;17:S125-30.

35 Liu J-E, Mok E, Wong T. Perceptions of Chinese cancer patients of the favorable and unfavorable words conveyed by their social support providers. Cancer Nurs 2005;28:348-54.

36 Helgeson VS, Cohen S, Schulz R, et al. Group support interventions for women with breast cancer: who benefits from what? Health Psychol 2000;19:107-14.

37 Devitt B, Hatton A, Baravelli C, et al. What should a support program for people with lung cancer look like? Differing attitudes of patients and support group facilitators. J Thorac Oncol 2010;5:1227-32.

38 Lo AC, Olson R, Feldman-Stewart D, et al. A patient-centered approach to evaluate the information needs of women with ductal carcinoma in situ. Am J Clin Oncol 2017;40:574-81.

39 Thewes B, Butow P, Zachariae R, et al. Fear of cancer recurrence: a systematic literature review of self-report measures. Psychooncology 2012;21:571-87

40 Mollica M, Nemeth L. Transition from patient to survivor in African American breast cancer survivors. Cancer Nurs 2015;38:16-22.

41 Myers SB, Manne SL, Kissane DW, et al. Social-cognitive processes associated with fear of recurrence among women newly diagnosed with gynecological cancers. Gynecol Oncol 2013;128:120-7.

42 Taylor TR, Huntley ED, Sween J, et al. An exploratory analysis of fear of recurrence among African-American breast cancer survivors. Int $J$ Behav Med 2012;19:280-7.

43 Gullett NP, Mazurak VC, Hebbar G, et al. Nutritional interventions for cancer-induced cachexia. Curr Probl Cancer 2011;35:58-90.

44 Bauer J, Jürgens H, Frühwald MC. Important aspects of nutrition in children with cancer. Adv Nutr 2011;2:67-77. 
45 Ota DM, Cox LC, Copeland III EM. Nutritional support of the cancer patient. In: Gunn AE, ed. Cancer rehabilitation. New York, NY: Raven Press, 1984: 121-36.

46 Gunn AE. Cancer rehabilitation. New York, NY: Raven Press, 1984.

47 Ravasco P, Monteiro-Grillo I, Marques Vidal P, et al. Impact of nutrition on outcome: a prospective randomized controlled trial in patients with head and neck cancer undergoing radiotherapy. Head Neck 2005;27:659-68.

48 Kang W-X, Li W, Huang S-G, et al. Effects of nutritional intervention in head and neck cancer patients undergoing radiotherapy: a prospective randomized clinical trial. Mol Clin Oncol 2016;5:279-82.

49 Fietkau R, Lewitzki V, Kuhnt T, et al. A disease-specific enteral nutrition formula improves nutritional status and functional performance in patients with head and neck and esophageal cancer undergoing chemoradiotherapy: results of a randomized, controlled, multicenter trial. Cancer 2013;119:3343-53.

50 Nixon DW. The value of parenteral nutrition support. Chemotherapy and radiation treatment. Cancer 1986;58:1902-3.

51 Shaharudin SH, Sulaiman S, Shahril MR, et al. Dietary changes among breast cancer patients in Malaysia. Cancer Nurs 2013;36:131-8

52 Bell K, Lee J, Ristovski-Slijepcevic S. Perceptions of food and eating among Chinese patients with cancer. Cancer Nurs 2009:32:118-26.

53 Geirsdottir OG, Thorsdottir I. Nutritional status of cancer patients in chemotherapy; dietary intake, nitrogen balance and screening. Food Nutr Res 2008:52.

$54 \mathrm{CS} \mathrm{H}$, Lun KC, WK N. The role of Chinese traditional medical practice as a form of health care in Singapore. Soc Sci Med 1984:18:745-52.

55 Ventola CL. Current issues regarding complementary and alternative medicine (CAM) in the United States: Part 1: the widespread use of $\mathrm{CAM}$ and the need for better-informed health care professionals to provide patient counseling. P T 2010;35:461-8.

56 Molassiotis A, Fernández-Ortega P, Pud D, et al. Use of complementary and alternative medicine in cancer patients: a European survey. Ann Oncol 2005;16:655-63.
57 Richardson MA, Sanders T, Palmer JL, et al. Complementary/ alternative medicine use in a comprehensive cancer center and the implications for oncology. J Clin Oncol 2000;18:2505-14.

58 Watkins CL, Fernandez-Robles C, Miller KM, et al. Use of complementary and alternative medicine by patients with cancer. Prim Care Companion CNS Discord 2011;13:PCC.10f01011.

59 Brown JK, Byers T, Doyle C, et al. Nutrition and physical activity during and after cancer treatment: an American cancer society guide for informed choices. CA Cancer J Clin 2003;53:268-91.

60 Sherwood PR, Donovan HS, Rosenzweig M, et al. A house of cards: the impact of treatment costs on women with breast and ovarian cancer. Cancer Nurs 2008;31:470-7.

61 Stanton M, Franco G, Scoggins R. Case management needs of older and elderly cancer survivors. Prof Case Manag 2012;17:61-9.

62 Veenstra CM, Regenbogen SE, Hawley ST, et al. A composite measure of personal financial burden among patients with stage III colorectal cancer. Med Care 2014;52:957-62.

63 Fenn KM, Evans SB, McCorkle R, et al. Impact of financial burden of cancer on survivors' quality of life. J Oncol Pract 2014;10:332-8.

64 Ministry of Health, Singapore. Licensing terms and conditions on provision of information on charges and financial counselling (report No. MH 50:01/2-3), 2011. Available: https://elis.moh.gov.sg/ elis/publishlnfo.do?task=download\&pkld=108 [Accessed 13 Feb 2017].

65 Zolnierek KBH, Dimatteo MR. Physician communication and patient adherence to treatment: a meta-analysis. Med Care 2009;47:826-34.

66 Davis MS. Variations in patients' compliance with doctors' advice: an empirical analysis of patterns $\mathrm{O}$ communication. Am J Public Health Nations Health 1968;58:274-88.

67 Fremon B, Negrete VF, Davis M, et al. Gaps in doctor-patient communication: doctor-patient interaction analysis. Pediatr Res 1971;5:298-311.

68 Mandl KD, Kohane IS, Brandt AM. Electronic patient-physician communication: problems and promise. Ann Intern Med 1998;129:495-500 